\title{
The Evaluation of Plant-Microbial Remediation of Petroleum Contaminated Soil
}

\author{
Wencui Ma ${ }^{1, a}$, Xue-yi You ${ }^{1, b}$, Xinxin Wang ${ }^{2, c}$, Yu Chen ${ }^{2, d}$ \\ ${ }^{1}$ School of Environmental Science and Engineering, Tianjin University, 300072 Tianjin, China \\ ${ }^{2}$ China Offshore Environmental Service Co., Ltd., 300072 Tianjin, China \\ amawencui0507@163.com, ${ }^{b} x y y o u @ t j u . e d u . c n,{ }^{c} w a n g x x @ c o e s . o r g . c n,{ }^{d}$ chenyu@coes.org.cn
}

Keywords: Soil remediation, Single factor index, Index system, Evaluation

\begin{abstract}
The efficiency evaluation of plant-microbial remediation of petroleum hydrocarbons (PHs) contaminated soil is investigated from two levels including single factor pollution risk and soil environmental quality comprehensive evaluation. The single factor index method was used to determine the risk level of PHs polluted soil. The comprehensive index method was used to determine soil quality improvement. The results show that the plant-microbial remediation has a good remediation effect. The topsoil is basically in the level of clean or slight pollution while the peak PHs concentration in soil depth is in the level of low-grade pollution. The soil fertility is improved to general level after restoration. The degree of potential risk is low.
\end{abstract}

\section{Introduction}

At present, developed countries has already built relatively sound soil remediation evaluation standards [1]. China starts late in soil restoration field and the relevant standards are not complete. The current Soil Environmental Quality Standard of China only concerns 8 heavy metals and 2 organic pollutants. It seriously lags behind the soil pollution status [2]. China launched out the technical guideline of Pollution Sites Risk Assessment in 1999, which was revised in 2014.

In the aspect of soil pollution remediation evaluation, Chinese and foreign scholars have made much progress [3-4]. For example, the single factor index method considers total pollutants as evaluation indices and determines the pollution levels by comparing total pollutants to environmental quality standard. However, the total residual pollutants are not comprehensive characterization of restoration effect of soil. Especially, new ecological risk may occur in the process of soil restoration and the soil properties may also change. Hence, there are theoretical and application significance to conduct a more reasonable evaluation of soil restoration effect with a combination of factors.

The soil remediation efficiency is studied by two levels including single factor pollution risk and environmental quality comprehensive evaluation of soil. The single factor index method is to determine the risk level of PHs polluted soil and the comprehensive index method is to determine the improvement of soil quality. The overall evaluation of the plant-microbial remediation efficiency on PHs contaminated soil is studied.

\section{Evaluation Index System}

Selection of Evaluation Indices. The evaluation includes two groups of tests: the control group and the remediation group with the equal amount of total PHs pollutions. The detailed experimental condition and data of evaluation come from the early study [5].

The evaluation indices of soil remediation efficiency are soil pollutant concentration, physical and chemical parameters, fertility and biological indices. The PHs is the main pollutant in oil field [6] and the impacts of specific PHs contaminants is neglected in the evaluation. Soil physical and chemical parameters include texture, bulk density (BD), $\mathrm{pH}$, salinity and heavy metals. Soils fertility indices include organic matter (OM), total nitrogen (TN) and phosphorus (TP), and available nitrogen (AN) and phosphorus (AP). The PHs pollution increase organic matter obviously. Biological indices 
include microbial population and vegetation coverage (VC). The heterotrophic plate counts (HPC) and PHs degradation bacteria counts (HDBC) are the potential indices that microbes decompose organic matter. The vegetation represents the function of soil ecosystem.

Remediation Standard. The Soil Environmental Quality Standard of China is formulated by using risk assessment method, where the basic value of soil environmental quality is achieved. So taking the national standard as the evaluation standard of remediation is reasonable and reliable.

The national standard divides the soil environmental quality into three categories. The soil quality in Dagang District of Tianjin belongs to the third type, which ensures agricultural production and the normal growth of plants [7]. After remediation, the PHs (total) concentration in the experimental field is required to satisfy the standard of agricultural land of $500 \mathrm{mg} / \mathrm{kg}$ at least. According to the second soil survey in China, the classification standard of soil nutrients content is shown in Table 1 [8].

Table 1 Soil fertility properties classification standard

\begin{tabular}{cccccccc}
\hline Threshold & $\mathrm{BD}\left[\mathrm{g} / \mathrm{cm}^{3}\right]$ & $\mathrm{pH}$ & $\mathrm{OM} \%$ & $\mathrm{TN}[\mathrm{g} / \mathrm{kg}]$ & $\mathrm{TP}[\mathrm{g} / \mathrm{kg}]$ & $\mathrm{AN}[\mathrm{mg} / \mathrm{kg}]$ & $\mathrm{AP}[\mathrm{mg} / \mathrm{kg}]$ \\
\hline$X_{a}$ & 1.45 & 9.0 & 1 & 0.75 & 0.4 & 60 & 5 \\
$X_{c}$ & 1.35 & 8.0 & 2 & 1.50 & 0.8 & 120 & 10 \\
$X_{p}$ & 1.25 & 7.0 & 3 & 2.00 & 1.0 & 180 & 20 \\
\hline
\end{tabular}

Evaluation Index System. The plumbum and cadmium content in soil are smaller than the limit values of heavy metal of the national agricultural soil of China and the salinity is $0.8 \%$, so their effect on the living beings in soil is neglected. The simulation shows that the PHs migrate little into deep soil layer and groundwater, so the PHs pollution effect to deep soil layer and groundwater is neglected [5]. The Suaeda isn't directly food for humans and acts mostly as livestock feed, so the direct influence of the adsorbed PHs of plant on human health is not considered. The soil total PHs, texture, bulk density, $\mathrm{pH}$, organic matter, total nitrogen and phosphorus, available nitrogen and phosphorus, microbial population and vegetation cover are chosen as evaluation indices. The evaluation index system is established and shown in Table 2. The index system consists of three basic parts including object level A, factor level B and index level C, totally 13 basic indices.

Table 2 Evaluation index system

\begin{tabular}{cccccccccccccc}
\hline A & \multicolumn{1}{c}{ B } & \multicolumn{1}{c}{ Remediation efficiency } \\
\hline \multirow{2}{*}{ B } & B1 & Pollutant & \multicolumn{4}{c}{ B2 } & \multicolumn{4}{c}{ B3 } \\
& \multicolumn{1}{c}{ Poltility indices } & \multicolumn{4}{c}{ Biological indices } \\
\hline \multirow{2}{*}{ C } & C1 & C21 & C22 & C23 & C24 & C25 & C26 & C27 & C28 & C31 & C32 & C33 & C34 \\
& PHs & Texture & BD & pH & OM & TN & TP & AN & AP & HPC & HDBC & HDBC/HPC & VC \\
\hline
\end{tabular}

\section{Evaluation of Remediation Efficiency}

Single Factor Index Evaluation. The risk assessment of PHs polluted soil is evaluated by the single pollution index method [9]. The quality grade of soil is expressed as:

$$
P_{i}=C_{i} / S_{i} \text {. }
$$

Where $P_{i}$ is single factor index, $C_{i}$ and $S_{i}$ are measured and simulated values of soil PHs concentration, separately. The grade of soil quality is divided as: $P_{i} \leq 1$, clean soil; $1<P_{i} \leq 2$, slightly polluted soil; $2<P_{i} \leq 3$, light polluted soil; $3<P_{i} \leq 5$, moderate polluted soil; $P_{i}>5$, heavily polluted soil.

The simulation shows that the residual PHs varies with the soil depth. Evaluating the soil quality by average PHs concentration in soil is not very appropriate. It ignores the gradient change of PHs concentration and lowers the local risk evaluation. In this study, the distribution of simulated pollution index is used to evaluate the local risk. The distribution of PHs pollution index after 180d experiment is shown in Figs. 1-2. 
The initial pollution index of soil is 10 in the control group, which belongs to heavily pollution level. The average pollution index is 4.7 at the end of the test, which belongs to moderate pollution level. However, the local maximum pollution index is 9.4, which belongs to heavily pollution level. The initial pollution index of soil is 4 in the remediation group, which is moderate pollution level. After remediation, the average pollution index is 1.1 , which is slight pollution level. The local maximum pollution index is 2.6 , which is light pollution level. The $15 \mathrm{~cm}$ topsoil becomes basically slight pollution-clean level after remediation.

The variance of pollution index is 0.97 in the remediation group, and 11.12 in the control group, respectively. It is concluded that although the average pollution index represents the average pollution level and the average remediation efficiency, it cannot represent the pollution level of local soil and the local pollution level is extremely high as shown in Figs.1-2.

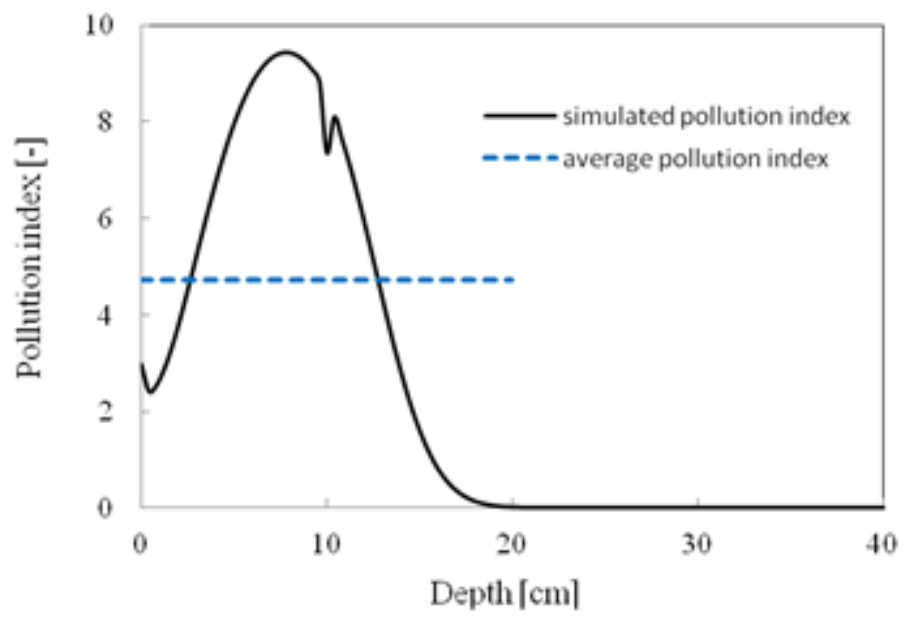

Fig. 1 The distribution of pollution index of control group with respect to soil depth after 180d experiment.

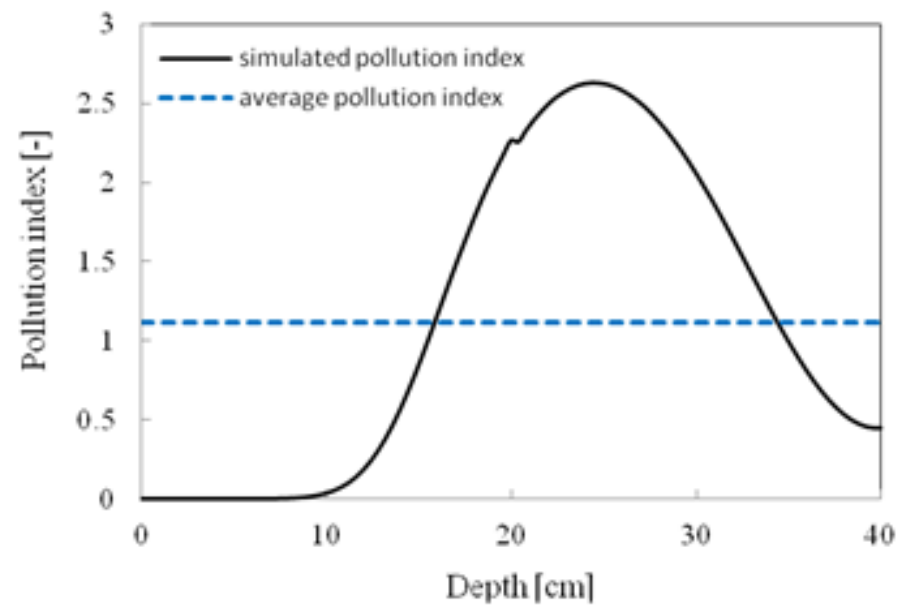

Fig. 2 The distribution of pollution index of remediation group with respect to soil depth after 180d experiment.

Soil Fertility Evaluation. The following modified Nemerow index method is used to evaluate the quality of soil fertility [9]:

$$
P=\sqrt{\left(\bar{P}_{i}^{2}+P_{\text {imin }}^{2}\right) / 2} \times\left(\frac{n-1}{n}\right), \quad \bar{P}_{i}=\sum_{i=1}^{n} P_{i} .
$$

Where $P$ is composite fertility index, $P_{\text {imin }}$ is the minimum fertility index, and $n$ is the number of indicators. The influence of worst evaluation index on the overall fertility is highlighted by using $P_{\text {imin }}$ in the equation. A correction term is added to improve the credibility level. The weight difference of each index is ignored. Standardizing the selected indices, eliminating the dimensional difference between indices, the method is written as [10]: 


$$
\begin{aligned}
& P_{i}=C_{i} / X_{a}, \quad C_{i} \leq X_{a} . \\
& P_{i}=1+\left(C_{i}-X_{a}\right) /\left(X_{c}-X_{a}\right), \quad X_{a}<C_{i} \leq X_{c} . \\
& P_{i}=2+\left(C_{i}-X_{c}\right) /\left(X_{p}-X_{c}\right), \quad X_{c}<C_{i} \leq X_{p} . \\
& P_{i}=3, \quad C_{i}>X_{p} .
\end{aligned}
$$

The $P_{i}$ of clay is 1 . The soil fertility indices of the two groups are shown in Table 3 . The fertility indices of each soil factor are given separately by 3, 2 and 1 to calculate the corresponding composite index of soil fertility. The result of classification of soil fertility is: $P \geq 2.63$, very fertile soil; $1.75 \leq P<2.63$, fertile soil; $0.88 \leq P<1.75$, general fertility soil; $P<0.88$, poor fertile soil. Due to the high PHs concentration of soil in the control group, the organic matter is increased obviously. Therefore, it is not taken as a evaluation index of soil fertility level in the control group. So the fertility classification changes to $\mathrm{P} \geq 2.57,1.71 \leq P<2.57,0.86 \leq P<1.71$ and $P<0.86$ for the above four levels.

After remediation, the composite index of soil fertility is 1.28 , which belongs to general level. The limiting factors are total and available nitrogen. This is because most of slow-release nitrogen fertilizer is taken up by plants. According to the law of Liebig minimum factor, appropriate supplementary of nitrogen will increase soil fertility and quality. Moreover, the $\mathrm{pH}$ of alkaline soil is reduced by $7.75 \%$ and the salinity-alkalinity of soil is lowered.

The soil composite fertility index in the control group is 0.83 , which belongs to poor level. It is found that the soil fertility level is raised by a level after remediation. The soil quality also improves to a certain degree. Besides, the nutrient of soil like $\mathrm{N}$ and $\mathrm{P}$ is high and this may also create a risk. Effective abundance and deficiency fertility indices are not overcapacity for both the control and remediation groups.

Table 3 The soil fertility indices of the control group and remediation group

\begin{tabular}{cccccccccccc}
\hline Indices & Texture & $\mathrm{BD}$ & $\mathrm{pH}$ & $\mathrm{OM}$ & $\mathrm{TN}$ & $\mathrm{TP}$ & $\mathrm{AN}$ & $\mathrm{AP}$ & $\overline{P_{i}}$ & $P_{\text {imin }}$ & $P$ \\
\hline Remediation group & 1 & 3 & 2.04 & 3 & 0.64 & 2.3 & 0.67 & 3 & 1.96 & 0.64 & 1.28 \\
Control group & 1 & 1 & 1.37 & - & 0.64 & 1.93 & 0.53 & 2.4 & 1.27 & 0.53 & 0.83 \\
\hline
\end{tabular}

Biological Index Evaluation. After the plant-microbial remediation, the vegetation cover reaches to $70-90 \%$. The soil properties are improved greatly. The total number of heterotrophic bacteria increases from $1.1 \times 10^{6} \mathrm{cfu} / \mathrm{g}$ to $3.9 \times 10^{6} \mathrm{cfu} / \mathrm{g}$. The petroleum hydrocarbon-degrading bacteria are increased to $7.2 \times 10^{5} \mathrm{cfu} / \mathrm{g}$. The number percentage of PHs degrading bacteria to that of total heterotrophic bacteria is increased from $0.1 \%$ to $18.5 \%$. The biodiversity in soil is enhanced, and the potential of organic matter decomposition is also increased.

\section{Conclusions}

(1) The topsoil of PHs contaminated soil is basically changed to the clean-slight pollution level by the plant-microbial remediation. However, the peak PHs concentration of soil is still at the level of light pollution, and further disposal is needed.

(2) The PHs contaminated soil is of poor quality. Compared with the control group, the soil fertility is improved one level to a general level after the remediation. It shows that the plant-microbial remediation promotes the soil properties.

(3) The evaluation results show that the plant-microbial remediation has little influence on the soil and surroundings. The degree of potential risk is low.

\section{Acknowledgements}


This work was supported by the science and technology program of Tianjin Binhai New Area (2012-XJR23017).

\section{References}

[1] J.X. Yuan, W. Zhang and Y. Dong: Science Press, Beijing (2011), p. 36 (In Chinese)

[2] Information on http://www.mep.gov.cn

[3] H.Y. Jiang, M. Liu and S.F. Huang: J. Saf. Environ. Vol. 4 (2005), p. 73 (In Chinese)

[4] T. Kaya, C. Kahraman: Eepert Syst. Appl. Vol. 38 (2011), p. 8553

[5] W.C. Ma, X.Y. You and X.X. Wang: submitted to Advanced Materials Research (2014)

[6] D. Hu, C. Li, Q.Q. Dong: Environ. Sci. Vol. 35 (2014), p. 227 (In Chinese)

[7] Information on http://www.tjdggt.gov.cn/Pages/dggt.aspx

[8] W.J. Shan, Q.T. Wu: Chin. J. Soil Sci. Vol. 25 (1994), p. 245 (In Chinese)

[9] C.O. Ogunkunle, P.O. Fatoba: Pol. Environ. Stud. Vol. 22 (2013), p. 487

[10] R. Xiao, J. Bai and Q. Wang: CLEAN-Soil, Air, Water Vol. 39 (2011), p. 612 